\title{
ESTIMATIVA DA ERODIBILIDADE DO SOLO PELO MÉTODO INDIRETO
}

\section{Dione Pereira Cardoso ${ }^{1}$ \\ Fábio Ribeiro Pires ${ }^{2}$}

Resumo: Objetivou-se avaliar a erodibilidade do solo pelo método indireto, baseado nas porcentagens de frações de areia, silte e argila, para quatro classes de solos de alguns municípios localizados no estado do Espírito Santo. Os dados das frações granulométricas do solo foram compilados do Projeto RADAMBRASIL. A equação utilizada para estimar o fator erodibilidade do solo é: Fator $\mathrm{K}=((\%$ areia $+\%$ silte) / (\% argila))/100. A erodibilidade do solo foi superior nos horizontes superficiais em relação aos subsuperficiais para todos os solos avaliados, sendo de 0,0133 tha $h \mathrm{ha}^{-1} \mathrm{MJ}^{-1} \mathrm{~mm}^{-1}$ (Latossolos), 0,0054 t ha $h \mathrm{ha}^{-1} \mathrm{MJ}^{-1} \mathrm{~mm}^{-1}$ (Chernossolos), 0,3556 tha $\mathrm{h} \mathrm{ha}^{-1} \mathrm{MJ}^{-1} \mathrm{~mm}^{-1}$ (Argissolos) e 0,0163 $\mathrm{t}$ ha $\mathrm{h} \mathrm{ha}^{-1} \mathrm{MJ}^{-1}$ $\mathrm{mm}^{-1}$ (Cambissolos). A correlação entre os horizontes foi de 0,999. Os valores de erodibilidade do solo foram superiores nos horizontes superficiais para todos os solos avaliados. Há diferença estatística entre as classes de solo em relação a sua erodibilidade. Há uma boa correlação da erodibilidade do solo dos horizontes superficiais e subsuperficiais.

Palavras-chave: Latossolos; Chernossolos; Argissolos; Cambissolos.

\footnotetext{
${ }^{1}$ Agronomia/Ceunes - UFES, Brasil. E-mail: cardoso.dione@gmail.com.

2 Agronomia/Ceunes - UFES, Brasil. E-mail: pires.fr@gmail.com.
} 